\title{
Formas regulatórias e participação infantil: marcas de descompassos nos momentos da roda na Educação Infantil
}

\section{Regulatory forms and child participation: marks of mismatches in moments of the wheel in Early Childhood Education}

\author{
Márcia Buss-Simão* \\ Aline Helena Mafra-Rebelo*
}

\begin{abstract}
RESUMO
Este texto traz contribuições de uma pesquisa desenvolvida em nível de mestrado, que assumiu como problemática investigar as formas regulatórias de uma instituição de Educação Infantil, utilizando procedimentos metodológicos provenientes da etnografia, como: registros escritos, fotográficos e fílmicos em uma instituição de Educação Infantil pública. A empiria, resultante da etnografia, se deu com um grupo de crianças de três a cinco anos de idade e os dados revelaram a presença de uma hierarquia posta a priori nas relações intergeracionais e consolidada sob a forma de regras institucionais. Analisou-se, portanto, um descompasso entre o direito das crianças à participação, bem como as regras institucionais postas no contexto, sobretudo no momento da roda de conversa proposta pelas professoras. Lançou-se mão dos estudos da Sociologia da Infância para constituir as análises, diálogo que permitiu considerar que a roda de conversa, apesar de ser tomada como uma possibilidade de promoção da participação de crianças no que tange às decisões em contexto educativo, precisa ser problematizada à luz dos eventos e de sua organização efetiva nas práticas educativas, com especial destaque aos tempos e espaços em que a roda de conversa era proposta para as crianças.

Palavras-chave: Educação Infantil. Formas regulatórias. Participação. Roda de conversa.
\end{abstract}

${ }^{*}$ Universidade Federal de Santa Catarina. Florianópolis, Santa Catarina, Brasil. E-mail: marcia.simao@gmail.com.https://orcid.org/0000-0001-6076-0640.E-mail: ahelenamafra@gmail. com. https://orcid.org/0000-0002-2391-9744. 


\begin{abstract}
This paper shares contributions of a research developed at master's level, which assumed as problematic to investigate the regulatory forms of an institution of Early Childhood Education, using methodological procedures from ethnography, such as: written, photographic and film records in a public early childhood. The empirical elements, resulting from the ethnography, occurred with a group of children from three to five years of age and the data revealed the presence of a hierarchy put a priori in intergenerational relations and consolidated in the form of institutional rules. It was analyzed, therefore, a mismatch between the children's right to participation and the institutional rules put in the context, especially at the moment of the round of conversation proposed by the teachers. The Sociology of Childhood studies were used to constitute the analyzes, a dialogue that allowed to consider that the talk wheel, despite being taken as a possibility to promote the participation of children in what concerns decisions in educational context, needs to be problematized to the light of the events and their effective organization in educational practices, with special emphasis on the times and spaces in which the talk wheel was proposed for the children.
\end{abstract}

Keywords: Child education. Regulatory forms. Participation. Moment of the wheel.

O reconhecimento da condição da criança e do adolescente como sujeito de direitos é um fato recente na história do Brasil, de modo que a defesa do direito à infância e à cidadania se constitui como um grande desafio da atualidade. No contexto brasileiro, a Constituição Federal (1988) reconhece a necessidade de proteção à infância, o direito à vida, à saúde, à alimentação, à educação, ao lazer, à cultura, à dignidade, ao respeito, à liberdade e à convivência familiar e comunitária, além de proteção de toda forma de negligência, discriminação, exploração, violência, crueldade e opressão. Contudo, Gonçalves (2015) destaca que o discurso da criança como sujeito de direitos se apresenta naturalizado, apenas como um 'slogan' das políticas públicas, que repercute na produção científica e nos debates acadêmicos, no sentido de repetir-se continuamente como um discurso fragilizado por duas razões: destituído de aprofundamento conceitual e distante das práticas sociais.

Como exemplos, citamos o caso da marginalização por parte dos adultos quanto ao direito à participação das crianças nas distintas esferas sociais que integram sua vida, seja na cidade, nos contextos educacionais-pedagógicos, entre outros. Assim, apesar do fortalecimento no campo do discurso (sobretudo político) acerca dos direitos à participação efetiva das crianças e jovens nestes contextos, segundo Gonçalves (2015), as vozes destes sujeitos sequer são con- 
sideradas pelos adultos nas práticas sociais, nas relações e decisões no âmbito da sociedade e, mais detidamente, nas práticas educativas desenvolvidas em contextos de institucionalização da infância.

James e Prout (1990, p. 8) alimentam essa discussão ao reconhecer as crianças como "ativas na construção de suas próprias vidas, as vidas dos que as rodeiam e das sociedades em que vivem. As crianças não são apenas os sujeitos passivos dos processos da estrutura social". Portanto, no que se refere ao campo de direito das crianças, evidencia-se a participação quanto às decisões que afetam sua vida no contexto educativo. Deste modo, a pesquisa que deu origem a este texto traz para o debate formas regulatórias inerentes ao funcionamento de uma instituição de Educação Infantil, com crianças de três a cinco anos de idade, que integravam o Grupo 4/5 de uma instituição de Educação Infantil da Rede Municipal de Florianópolis (SC) no ano de 2014. E, ao trazê-las, tenciona os modos pelos quais a participação das crianças ocorria em um momento constitutivo da rotina das crianças: a roda de conversa.

Metodologicamente, a aproximação e posterior desvelamento dos modos como a roda se torna um instrumento regulatório se tornou possível por meio de uma pesquisa etnográfica cujos instrumentos utilizados foram registros fotográficos, fílmicos e escritos compartilhados com as crianças ao longo de todo o processo de pesquisa empírica. A fim de compreender o modo como as crianças vivem esse contexto por meio de uma pesquisa etnográfica, foi fundamental conferir atenção não à criança como sujeito isolado, mas a uma investigação com crianças que englobe duas dimensões primordialmente: a experiência social e as crianças e suas ações e significações dentro do contexto de relações, considerando que elas possuem uma multiplicidade de formas de agir, dependendo do contexto cultural e social em que estão imersas (ROCHA, 2008).

No âmbito deste artigo, privilegiaremos como fonte de dados os registros escritos gerados ao longo de seis meses de empiria, cujo foco de análise foram as situações vividas por crianças e profissionais durante a roda de conversa, momento constitutivo da rotina do Grupo 4/5. Evidenciamos, a partir da empiria, um descompasso entre o direito das crianças à participação e as regras institucionais postas no contexto, sobretudo no momento da roda de conversa proposta pelas professoras do Grupo 4/5. Logo, as dimensões e os elementos que compõem este descompasso, anunciados por meio de registros escritos, subsidiarão o foco do presente texto.

Em cumprimento às questões éticas inerentes à pesquisa postas tanto pelo Comitê de Ética institucional quanto em respeito ao acúmulo de produção de conhecimento da área, em relação à identificação nominal das crianças optamos por manter seus nomes verídicos na tessitura dos registros escritos, entendendo esta ação como respeitosa à sua identidade, suas particularidades e formas de ser. 
Reconhecemos esta como uma ação que visa contribuir para o fortalecimento e legitimação das vozes das crianças como informantes privilegiados na pesquisa, considerando-as como sujeitos que merecem sua identidade registrada, sem com isso, expô-las a situações constrangedoras. Já a escolha pelo Grupo 4/5 (no caso desta unidade, constitui-se como o grupo que reúne crianças de 4 a 5 anos de idade), se deu pela hipótese de, pelo tempo de permanência na instituição educativa, maior familiaridade e intimidade com a rotina e, consequentemente, com as regras e normas do contexto.

\title{
A instituição de Educação Infantil e suas formas regulatórias: do direito à participação às práticas pedagógicas
}

\author{
"Não é questão de querer, nem questão de concordar. \\ Os direitos das crianças, todos têm de respeitar!"
}

Ruth Rocha

Sob a lógica da escritora brasileira, Ruth Rocha, buscaremos travar um diálogo acerca da infância como tempo de direitos e as crianças como sujeitos de direitos. Assim, para além da legalidade e estatuto de direitos às crianças atribuído, compreendemos que a sua garantia no campo das práticas pedagógicas na Educação Infantil ainda se encontra em disputa, sobretudo à luz da insistente predominância de uma lógica adultocêntrica nestes contextos. Fernandes (2005, p. 2) contribui a essa discussão ao considerar que:

A tarefa de atribuir direitos à criança tem tido um longo e, muitas vezes, tortuoso caminho, quer devido à lenta consciencialização da sociedade acerca de tal necessidade, quer devido às dificuldades que se colocam à interpretação e aplicação de direitos para as crianças em contextos culturais diversos e em épocas históricas distintas.

Contudo, aqui compreendemos que estes direitos, nomeadamente a proteção, provisão e participação (postos na Convenção sobre os Direitos da Criança em 1989) à brincadeira, ao respeito, à alteridade (apresentados em políticas públicas nacionais) e à educação de qualidade (apresentada pela Constituição da República de 1988), precisam ser garantidos tanto na Educação Infantil, 
quanto em outros contextos formais de educação que atendam a infância. Portanto, torna-se possível reconhecer o necessário esforço em garantir os direitos desses sujeitos de pouca idade como um ato político tão necessário em tempos de perda de direitos sociais e retrocessos, com os quais o Brasil vem sendo afetado sobretudo a partir de 2016, após o golpe parlamentar, ao qual a presidenta Dilma Rousseff foi submetida.

Nesta discussão, pretendemos evidenciar o direito à participação das crianças no contexto educativo e sobre questões que afetam e envolvem diretamente suas vidas, sem, contudo, desconsiderar as questões sublinhadas por Cervi (2010), no que se refere aos cuidados necessários quanto ao apelo à participação. A autora alerta para os perigos de sua banalização, pois, no mundo Moderno, a grande necessidade que se impõe é controlar tudo e todos por meio inclusive de mecanismos de participação em que os sujeitos são convocados a aprender técnicas democráticas para conviver em harmonia, atingir o consenso, serem tolerantes e finalmente serem convencidos de que "todos" participam de uma sociedade plena de direitos.

Trazendo também para este debate as considerações de Fernandes (2005), reconhecemos que a garantia do direito das crianças à participação, sobretudo no que se refere ao direito de ser consultada e ouvida, à liberdade de expressão e opinião e ao direito a tomar decisões sobre a realidade social que vive, encontra-se em uma encruzilhada no contexto das práticas sociais, com destaque, para as educacionais-pedagógicas constitutivas da Educação Infantil. Assim, assumimos que garantir a participação das crianças no contexto educativo se configura como uma prática processual e contínua que ocorre na relação intergeracional.

Partir do reconhecimento do direito à participação como uma defesa política acerca da cidadania das crianças leva-nos a chamar para o debate questões acerca das formas regulatórias constitutivas da instituição de Educação Infantil, na qual a pesquisa foi desenvolvida que demarcaram e contornaram, sobremaneira, o direito à participação das crianças que frequentavam o Grupo 4/5. Vale destacar que o conceito de formas regulatórias foi assumido a partir dos estudos de Boaventura de Sousa Santos (2002), que as compreende como uma racionalidade que, por meio de regras e normas, impõe um modo de vida aos sujeitos Modernos, constituindo-se como um dos alicerces do projeto sociocultural Moderno. Nessa perspectiva, a roda de conversa é concebida como um momento potente para a garantia do direito à participação das crianças, mas, no desenvolvimento das práticas pedagógicas levadas a efeito no contexto investigado, problematizamos as formas regulatórias que colocam este direito em xeque.

No âmbito do cotidiano educativo, no decorrer da investigação empírica, que ocorreu durante seis meses no contexto de uma instituição de Educação Infantil pertencente à Rede Municipal de Ensino de Florianópolis, sempre em nossa 
chegada buscávamos apreender a organização de seu tempo e espaço e conhecer as responsabilidades de cada profissional que ali atuava, observando por algum tempo a rotina institucional, ou seja, uma organização que ia além da estabelecida pelas professoras ao Grupo 4/5 (cuja pesquisa ocorreu de forma mais próxima). Por meio de observações e algumas conversas informais com os profissionais, aproximamo-nos da realidade do contexto investigado e conhecemos certas histórias da comunidade na qual a instituição estava localizada, bem como alguns desafios que a mesma enfrentava em relação ao espaço físico.

Paulatinamente, fomos nos apropriando do cotidiano institucional de forma geral e não somente da rotina das crianças e professoras do Grupo 4/5. Assumimos esta ação como necessária, visto que o grupo de crianças em que a pesquisa foi realizada não estava alienado de um contexto mais alargado que abarca outras relações, gerando interdependências. Assim, entendemos que esta ação foi necessária visto que as formas regulatórias atuam de maneira a direcionar e conduzir a vida dos sujeitos no contexto da Modernidade.

A relação e vivência no campo possibilitou compreender que as formas regulatórias presentes no contexto investigado se materializavam por meio de regras e normas que eram determinadas às crianças de todos os grupos da instituição de Educação Infantil em que a pesquisa foi desenvolvida, a fim de organizar a rotina de maneira geral, enquanto outras eram restritas e específicas do Grupo 4/5. Para que a ordem fosse mantida e o caos contido, os profissionais da instituição lançavam mão de instrumentos e estratégias, exigindo das crianças o cumprimento de regras como: fazer silêncio, não correr, comer de boca fechada, não levantar durante as refeições, respeitar o colega e as professoras, não empurrar, pedir o brinquedo emprestado, deitar para descansar na hora do sono etc.

Nesse contexto de convivência entre sujeitos singulares, diferentes, pertencentes a categorias geracionais distintas, a lógica da Modernidade, a qual todos (as) estão imersos, faz que os adultos concebam o caos, ou seja, qualquer outra organização que não seja ordenada, sistematizada, disciplinada como algo que foge ao que se deseja para qualquer instituição coletiva. Imbuídos por esta lógica, os profissionais que atuam na instituição acabam inferindo às crianças organizações ordenadas, sistematizadas e padronizadas que não podem fugir à regularidade já instituída. Isso significa afirmar que muitas vezes a disciplina é utilizada como forma de estabelecer esse ordenamento, sem que haja uma reflexão ou uma tomada de consciência sobre os motivos dessa exigência.

Entretanto, contrariamente ao que pela Modernidade é inferido, é necessário que se permita o caos, ou seja, eventos e situações que fogem a uma regularidade instituída pelos adultos, com vistas a mobilizar posicionamentos críticos e criativos das crianças. Isto implica em uma desordem no sentido de 
uma fuga ao que é tido como regulador das atividades que ocorrem na instituição, mas que visa proporcionar vivências emancipatórias. Mas, para que isto ocorra, é preciso que se tenha em mente o conceito de trabalho de tradução, o qual é capaz de criar uma inteligibilidade entre experiências disponíveis e possíveis a partir do diálogo entre os sujeitos com distintos pontos de vista, valores e/ou crenças (SANTOS, 2002). Deste modo,

A tradução é o procedimento que permite criar inteligibilidade recíproca entre as experiências do mundo, tanto as disponíveis como as possíveis, reveladas pela sociologia das ausências e a sociologia das emergências. Trata-se de um procedimento que não atribui a nenhum conjunto de experiências nem o estatuto de totalidade exclusiva nem o estatuto de parte homogênea. As experiências do mundo são vistas em momentos diferentes do trabalho de tradução como totalidades ou partes e como realidades que se não esgotam nessas totalidades ou partes. Por exemplo, ver o subalterno tanto dentro como fora da relação de subalternidade (SANTOS, 2002, p. 262).

Refletir sobre as instituições educativas, à luz destes conceitos, constitui-se como um grande desafio, visto que a visão moderna sobre as crianças ainda é marcada pelo adultocentrismo, ou seja, às crianças não é conferido o estatuto de sujeitos competentes para falarem por si mesmas, tampouco para tomarem decisões sobre eventos que envolvem suas vidas. Um trabalho de tradução implica o diálogo entre sujeitos pertencentes a distintas categorias geracionais na resolução de conflitos, sem haver desperdícios de experiências. Visa que um grupo tenha conhecimento sobre os interesses do outro e isto implica, no caso dos grupos geracionais que estão presentes nas instituições de Educação Infantil, o reconhecimento legítimo das crianças como informantes privilegiados sobre sua realidade. Esse reconhecimento exige a necessidade de auscultar as crianças, conforme apontado por Rocha (2008), para junto com elas, construir modos organizacionais do cotidiano educativo, a fim de buscar alternativas outras ao conceito de caos.

[...] auscultar as crianças implica o sentido de reconsideração de seu espaço social, ou seja, 'ouvi-las' interessa ao pesquisador e ao educador como forma de conhecer e ampliar sua compreensão sobre as culturas infantis - não só como fonte de orientação para a ação, mas sobretudo como forma de estabelecer uma permanente relação comunicativa - de 
diálogo intercultural - no sentido de uma relação que se dá entre sujeitos que ocupam diferentes lugares sociais (ROCHA, 2008, p. 47).

Nesse sentido, faz-se oportuno indicar que as crianças, ao chegarem no mundo, já estão imersas em um contexto social, cultural e histórico construídos a priori em relação ao seu nascimento. E tal prerrogativa vai ao encontro de questões debatidas e complexificadas pelo campo da Geografia da infância, que reconhece as crianças como cidadãos de direitos à cidade.

A Geografia da infância se trata de um campo de estudos bastante recente e ainda em constituição. Seu início se deu data da década de 1960, no contexto estadunidense (LOPES, 2013). Convém ressaltar que no Brasil há pesquisas pontuais, nomeadamente sob os estudos de Jader Lopes. Este campo fornece elementos para problematizações acerca da forma de constituição do mundo, o qual é organizado e pensado para contemplar as especificidades dos adultos e não dos sujeitos de menor idade. Como claros exemplos, pode-se citar a arquitetura e o urbanismo das cidades, que são planejadas levando em consideração a anatomia e necessidades dos adultos, marginalizando assim, o direito de as crianças viverem plenamente à cidade.

Questões demarcadas pela Geografia da Infância também apontam para interrogações acerca das distintas temporalidades das crianças e dos adultos e provocam questionamentos, os quais: Como nos relacionamos com as crianças de modo que elas se sintam partícipes do contexto educativo e das demais esferas sociais? O quanto nos permitimos afetar pelas contribuições das crianças?

Admitindo o risco de buscar uma interlocução com tais questões, no sentido de não apresentar respostas acabadas, mas pistas e possibilidades, indicamos que o que nos torna igual às crianças é a nossa humanidade, que precisa ser reconhecida na relação educativa estabelecida entre as distintas categorias geracionais. Tal reconhecimento exige um olhar sensível à infância e as dimensões sociais, culturais, étnicas e de gênero que a constitui.

E, neste processo de afirmação e reconhecimento acerca da necessidade de ausculta e reconhecimento das vozes infantis quanto às organizações do cotidiano educativo, durante a empiria, diversos foram os momentos em que as crianças, atendendo à solicitação das professoras, reuniam-se em roda para ouvir - e não participar - sobre a rotina diária. Tais momentos, especificamente, foram trazidos à tona visto seu potencial de análise e interface com o direito à participação, pois a chamada para a roda vem sendo considerada, no campo das práticas docentes, como um momento fundamentalmente participativo e que confere voz e vez às crianças. Contudo, cabe aqui tensionar esta questão à luz dos registros empíricos em diálogo com estudos da Sociologia da Infância. 


\section{Momento da roda: participação ou imposição?}

Chegamos à sala referência e as crianças estavam brincando livremente. Minutos depois, a professora pede para que todas guardem os brinquedos. Em meio a movimentação, Laís se aproxima e pede: - Aline, pega o meu caderno 'pra' mim? No mesmo instante, Ana Carolinny diz: - Não Aline! A gente já vai 'pra' roda! (Notas de campo - junho de $2014-9^{\circ}$ dia).

Momentos como o descrito foram frequentemente vividos na relação com as crianças no contexto educativo. $\mathrm{O}$ reconhecimento da roda como uma parte constitutiva da rotina era constante nos diálogos estabelecidos entre os pares de meninas e meninos do Grupo 4/5, despertando, assim, o interesse de pesquisa à esta organização e suas propostas inerentes. Para dar início aos debates acerca do momento da roda, trazemos à tona contribuições de Barbosa (2000), que, ao discutir sobre a configuração das rotinas presentes na Educação Infantil, indica que uma ideia frequentemente relacionada a elas é a sequência temporal, evidenciando-as como "ações ou os pensamentos - mecânicos ou irrefletidos realizados todos os dias da mesma maneira, um uso geral, um costume antigo ou uma maneira habitual ou repetitiva de trabalhar" (BARBOSA, 2000, p. 48).

Nesse contexto, a rotina é vista como a espinha dorsal, a parte fixa do cotidiano da instituição de Educação Infantil, em que está implícita uma noção de espaço e de tempo: "De espaço, na medida em que trata de uma rota de deslocamentos espaciais previamente conhecida - como são os caminhos, as rotas; e de tempo, por tratar-se de uma seqüência que ocorre com determinada freqüência temporal" (BARBOSA, 2000, p. 52).

Os estudos de Barbosa (2000) revelam que a rotina é adquirida pela prática, pelos costumes, não sendo necessário nenhum tipo de justificativa, razão ou argumentação teórica para a sua efetivação. Desse modo, a rotina está intimamente ligada aos rituais, aos hábitos e às tradições e nem sempre deixa espaço para a reflexão. A rotina, e seus rituais, se trata do objeto de pesquisas desenvolvidas junto à Rede Municipal de Educação Infantil de Florianópolis, a exemplo de Batista (1998) e Agostinho (2003), as quais contribuíram fundamentalmente para as análises tecidas pela pesquisa que deu origem a este texto. Assume-se, portanto, um diálogo mais próximo às pesquisas desenvolvidas localmente, 
sem com isso negar o conhecimento de pesquisas sobre rotina desenvolvidas nacionalmente, a exemplo de: Rodrigues (2009), Moura (2012), Souza (2013), Nascimento (2015) e Borges (2017).

No que se refere à realidade de Florianópolis (SC), a dissertação de mestrado de Batista (1998) apontou que a rotina, estrutura entendida como gerenciadora do tempo-espaço da creche, muitas vezes obedece a uma lógica institucionalizada nos padrões da pedagogia escolar que se impõe sobre as crianças e sobre os adultos, que vivem grande parte do tempo de suas vidas nesta instituição. A pesquisa, também em nível de mestrado, realizada por Agostinho (2003), pretendeu conferir visibilidade ao ponto de vista das crianças para buscar as "pistas" que elas apontam para se pensar sobre os espaços coletivos na Educação Infantil. Os estudos de Agostinho (2003) indicaram que, ao conhecer a forma como o espaço da creche se transforma em lugar socialmente construído nas relações que ali são travadas entre as crianças e os adultos que a habitam, as crianças desejam que a creche seja um lugar de brincadeira, de liberdade, de movimentos, de encontros e um lugar para estar a sós.

Nos encontros entre a rotina institucional e as relações travadas entre crianças e adultos no momento da roda de conversa, aproximamo-nos dos estudos desenvolvidos por De Ângelo (2013), Motta (2013) e Rosa (2018), que analisam esse momento enquanto um dispositivo pedagógico, como prática dialogada e enquanto um lugar de encontro entre crianças e adultos, revelando a pertinência da discussão dessa temática pela "necessidade de se desenvolverem mecanismos que possibilitem a expressão das crianças como elemento organizador das práticas pedagógicas" (MOTTA, 2013, p. 67).

Convém indicar que o momento da roda ${ }^{1}$ integrava fundamentalmente a rotina do Grupo 4/5, sendo instituído diariamente no período matutino e vespertino. Nesses momentos, era exigida a presença de todas as crianças, sendo-lhes apresentada (e não discutida ou debatida) a organização do dia. Essa organização também contava com momentos reservados para a leitura de algum livro, ou para a apresentação das crianças sobre algum tema específico que integrava o planejamento das professoras.

Durante o momento da roda, as professoras pediam que as crianças se sentassem lado a lado com "perninha de índio", ou seja, com as pernas dobradas e cruzadas. Vale indicar que a primeira organização deste momento permitia que as crianças se sentassem no lugar e ao lado da companhia que lhes agradava. Contudo, no instante em que as professoras observavam alguma conversa ou brincadeira entre as crianças, exigiam que elas imediatamente trocassem de lugar, buscando, com isso, afastar os pares que eventualmente causavam tumulto

1 Assim eram nomeados pelas professoras e crianças do Grupo 4/5. 
no momento da roda ou inferir regras de silêncio especialmente pensadas para este momento.

Todas as crianças sentam-se na roda, enquanto a professora avisa que o combinado agora é ouvir e começa a falar sobre a localização das casas das crianças. Sentado na roda, Jeferson fala em voz alta, na intenção de pedir a vez para falar. Neste momento a professora se dirige ao menino: - Jeferson, gritar não funciona aqui. Levantar a mão funciona, porque se todo mundo falar ao mesmo tempo ninguém se entende (Notas de campo - junho de $2014-13^{\circ}$ dia).

À luz deste evento, compreendemos que o momento da roda era permeado por regras especificamente postas pelas professoras e destinadas a organizar o modo como as crianças deveriam nela se portar. Deste modo, indicamos que o momento da roda integrava a rotina diária das crianças, sendo proposta pelas professoras do Grupo 4/5, marginalizando a participação e voz dos meninos e das meninas do grupo. Frente a isto, torna-se necessário trazer novamente as contribuições de Barbosa (2000, p. 53), que, ao problematizar as rotinas instituídas no contexto da Educação Infantil, sugere:

Ainda pode ser apontado como característica das rotinas o fato de elas conterem a idéia de repetição, de algo que faz resistência ao novo, e que recua frente à idéia de transformar. E também que as rotinas são feitas a partir de uma sequência de atos ou conjunto de procedimentos associados que não devem sair da sua ordem; portanto, as rotinas têm um caráter normatizador.

O momento da roda, que constituía a rotina dos sujeitos que compunham o Grupo 4/5, pode ser visto como uma forma regulatória do contexto da Educação Infantil, proposta pelos adultos de forma hierárquica que, por vezes, ao não oferecer alternativas às crianças, configura-se como um evento cristalizado no contexto educativo. Isso significa considerar que o momento da roda, apesar de sua intencionalidade enquanto organização a fim de promover a participação dos meninos e das meninas do Grupo 4/5, encontra-se em tensionamento com o modo como é efetivamente proposto no contexto da Educação Infantil, em que às crianças, por vezes, somente se exige ou se possibilita a integração (o que não implica participação) na roda. Assim, para De Ângelo (2013), o momento 
da roda tem sido considerado como um importante dispositivo pedagógico, mas, extremamente desafiante.

E sobre os desafios constitutivos do momento da roda, compreendemos que um dos mais complexos, no contexto investigado, revelava-se na dificuldade dos adultos em conceber a participação efetiva das crianças do Grupo 4/5 nas decisões coletivas, que, por sua vez, afetavam o todo e, também, cada um em particular. Ou seja,

O desafio é estar vigilante para que essa vivência se estabeleça verdadeiramente como momento de construção e de troca dialógica entre diferentes sujeitos, e não como um momento trivial, rotineiro e mecânico, engessando toda a riqueza do diálogo num momento ritualístico em que a criança vai receber, por parte do adulto, apenas orientações e normas a serem seguidas, sanções a serem cumpridas (DE ÂNGELO, 2013, p. 61).

Durante o período da pesquisa de campo na instituição, não foram presenciados momentos em que a roda fosse apresentada às crianças como uma opção, pelo contrário, como uma exigência, a exemplo do episódio apresentado na sequência:

A professora pede para as crianças guardarem os brinquedos para formarem a roda. As crianças aos poucos guardam os brinquedos nos devidos lugares e sentam-se no tapete. Contudo, Alícia continua fazendo sua atividade de recorte na mesa. As demais crianças formam a roda e ela permanece na mesa. Então, uma das professoras começa a conversar com as demais crianças, enquanto o outro adulto se aproxima de Alícia e pede que ela guarde aquele material e se junte às demais crianças na roda (Notas de campo - junho de $2014-4^{\circ}$ dia).

A narrativa nos convida a refletir novamente sobre o momento da roda como espaço organizado e proposto pelos adultos para as crianças e não sistematizado junto com elas, pois, se assim o fosse, o direito de Alícia terminar sua atividade livre durante o momento da roda, seria respeitado. A hora da roda na rotina do Grupo 4/5 já estava predefinida em termos de horário (entre $9 \mathrm{~h}$ e 9h30min), local (sala de referência do grupo) e organização (círculo entre as crianças sentadas com as pernas cruzadas). E, mesmo diante de demandas e 
interesses distintos, manifestos pelas crianças, este momento desenhado pelas professoras era por elas mantido.

Os estudos de Batista (1998) nos provocam a refletir se a roda, nesse modo de organização, não se configura como uma tarefa a ser cumprida pelo adulto? A autora analisa o momento da roda como elemento da rotina, que tem como centralidade manter as crianças ocupadas em ficarem sentadas, ouvirem, obedecerem. Batista (1998) chama também a atenção para o fato de que a roda de conversa parecer ser o meio para preparar as crianças para a realização da "atividade pedagógica" a qual, equivocadamente, tem sido compreendida na área como o momento sério e mais nobre dos processos educativos.

A roda parece configurar-se como um momento que marca a transição entre a atividade livre e a atividade considerada séria; entre o "estado de esquina de rua" e o "estado de estudante"; entre o movimento espontâneo e o movimento controlado; o espaço transitório e o espaço fixo; o tempo heterogêneo e o tempo homogêneo (BATISTA, 1998, p.78).

Glenda Rosa (2018), duas décadas após o desenvolvimento da pesquisa de Batista (1998), ao aproximar-se da realidade vivida por crianças pequenas na Educação Infantil de uma instituição de Brasília, tece considerações semelhantes sobre a roda de conversa. A autora revela que a conversa nem sempre ocupava o lugar de privilégio na roda de conversa. Por vezes, o que se dava era uma roda em que as crianças eram conduzidas a responder perguntas ou falar sobre o que as professoras perguntam, de forma breve e regulada. Esta organização permitiu considerar o momento da roda como reflexo de uma sociedade produtivista e que acelera cada vez mais o tempo, privilegiando o produto em detrimento da valorização do processo. A autora ainda destaca que "nas rodas de conversa que observei e nas oficinas realizadas, havia um tipo de linguagem, um tipo de conversa mais valorizada pelas educadoras: a conversa imersa em uma linguagem pedagogizante, vazia de encontro e de experiência" (ROSA, 2018, p. 133, grifos no original).

Em contrapartida ao momento da roda perspectivado como um espaço de imposição de uma lógica adultocêntrica sobre os sujeitos de menor idade, defendemos a concepção deste espaço como privilegiado para a troca de experiências e conhecimentos, de promoção de diálogos, negociação, afetividade, encontros e construção de conhecimentos coletivos e de garantia de participação de todos os envolvidos nos processos educativos. 
Compreendemos que o momento da roda no contexto da Educação Infantil precisa assumir a dimensão de um espaço democrático em que crianças e adultos compartilhem experiências, saberes, opiniões e sentimentos e sobretudo exercitem seu direito à participação, já previsto pela Convenção dos Direitos das Crianças (1989). Contudo, este momento, ao adotar um caráter diário e repetitivo, perde a essência de um espaço destinado às interações e a troca de experiências, assumindo a configuração de um instrumento de regulação das ações e opiniões das crianças. A iniciativa de organizar o momento da roda deve envolver todos os sujeitos do Grupo 4/5, fugindo do formato atual, em que as professoras chamavam todas as crianças para a roda e instituíam a elas a pauta da conversa e os encaminhamentos do dia.

A persistente cultura de desrespeito da criança activa e participativa, a que continuamos a assistir, assume, por vezes, contornos dúbios, através da encenação de falsos ambientes de participação infantil, onde a voz das crianças, por vezes, até pode ser ouvida mas não escutada, onde os discursos revelam palavras adultas através da fala das crianças, etc. (FERNANDES, 2005, p. 394).

A esse respeito, torna-se urgente apontar que os momentos da roda sejam problematizados à luz do direito de participação das crianças a decisões que envolvem suas vidas (preocupação que ocupa destaque nos estudos da Sociologia da Infância). Conforme indica Fernandes (2005), é no âmbito do discurso acadêmico que se torna possível recuperar o paradigma da participação infantil. O discurso acadêmico sobre os direitos das crianças, construído sobretudo nas últimas décadas, vem:

Tentado ultrapassar as velhas retóricas dos direitos como 'utopias' e umbilicalmente ligado aos paradigmas defendidos pela sociologia da infância, ou seja, à necessidade de encarar a infância como uma construção social e as crianças como actores sociais, competentes, activos e com 'voz', começa a tornar visíveis preocupações que até há bem pouco tempo não faziam parte das agendas de investigação (FERNANDES, 2005, p. 7).

Faz-se necessário que haja análises cada vez mais extensivas sobre a necessidade de momentos como a roda, tal qual como estava organizada no contexto educativo investigado, ou seja, de forma diária e recorrente. Assumimos 
então, que organizar a roda e convocar as crianças não garante aos meninos e meninas participarem das decisões diárias, tampouco que façam sugestões que modifiquem a rotina instituída.

Os momentos de roda precisam ser entendidos como espaços para o encontro, para a troca de experiências e escuta entre professoras e crianças, de modo a não exigir sempre a presença de todos/as. A partir do momento em que as professoras definem esta exigência como uma regra do grupo, nega-se às crianças o seu direito à participação e o momento da roda assume um caráter regulatório. $\mathrm{O}$ direito à participação e à cidadania se encontram em risco à medida em que são naturalizadas práticas como uma roda de conversa que invisibilize e banalize os processos de participação das crianças. Com isto, evidenciamos que, apesar da concretude de discursos acadêmicos, legais e políticos em prol dos direitos das crianças, as ações e práticas a elas dirigidas ainda estão distantes de sua concretização.

Nesse contexto, o momento da roda enquanto espaço de diálogos e encontros constitui-se como uma potente possibilidade para proporcionar e garantir a participação dos sujeitos de menor idade acerca de questões que trazem implicações diretas em suas vidas, onde:

A sua importância se justifica pelas possibilidades que proporcionam para o exercício da responsabilidade individual e coletiva, o estabelecimento de metas e normas, a administração de problemas e conflitos, a tomada de decisões coletivamente e a prática da democracia (DE ÂNGELO, 2013, p. 61).

Desse modo, reconhecemos que o momento da roda precisa ser repensado à luz de seu fundamental caráter democrático e participativo, em um movimento constante em se afastar de formas autoritárias de sistematizá-lo no contexto das práticas educativas na Educação Infantil.

Propor e sistematizar na rotina um momento para o diálogo, encontro, afetos e participação das crianças no contexto da Educação Infantil, trata-se de um constante e recorrente desafio (que atravessa a territorialidade do município de Florianópolis), em que o momento da roda vem sendo assumido como seu escape ou sua "solução". Porém, a forma como sua proposição se configura, enviesa a compreensão de cidadania das crianças no contexto em que habitam, reduzindo sua participação à obrigatoriedade e regulação de um modo único de ser e estar na roda. 
Essas discussões são fortalecidas também com base em eventos e organizações do momento da roda vividos no contexto da pesquisa de campo realizada, em que a professora propunha o momento da roda para apresentar a rotina aos meninos e as meninas do Grupo 4/5, em que seus corpos precisavam também ser regulados para "enquadrar-se" na roda e na sua regulação.

A professora explica que amanhã o grupo de crianças fará um passeio e pede que as crianças fiquem em silêncio para que ela possa falar um pouco sobre isso. Ana Carolinny e Lara se deitam na roda, momento em que a professora diz:

- Vamos combinar de encolher as pernas, se não, não cabe todo mundo. As meninas fazem isto, mas logo em seguida Ana Carolinny se deita novamente. Enquanto a professora fala, Davi e Iago conversam entre si e Jeferson se senta no meio da roda. Em seguida, a professora começa a apresentar um livro e pede que as crianças cheguem mais perto dela. Chama a atenção de Ana Carolinny e Lara.

- Vocês duas não param na roda!

Jeferson se aproxima de Davi e belisca o nariz do colega. No mesmo instante, a professora chama a atenção de Jeferson, de forma séria:

- Davi, você pediu pro Jeferson te beliscar?

Davi responde:

- Não.

A professora continua:

- Então por que você fez isso Jeferson? Que coisa!

Em seguida, fala para todas as crianças:

- Quem não se comportar eu vou tirar da roda. Aline, pode escrever quem eu vou tirar tá?! (Notas de campo - julho de 2014 $\left.-21^{\circ} \mathrm{dia}\right)$.

O episódio descrito foi fruto de experiências vividas no ano de 2014 em uma instituição de Educação Infantil pertencente à Rede Municipal de Florianópolis, demarcada e constituída social, geográfica e historicamente. Porém, organizações semelhantes já foram apresentadas e analisadas pela pesquisa de mestrado de Rosa Batista, em 1998, em que a autora revelou momentos em que a professora de Educação Infantil chamava as crianças a compor a roda de conversa, trazendo nesse bojo, problematizações importantes e necessárias. Acerca disto, Batista (1998, p. 67) analisou que: 
A hora da roda é o momento em que o tempo da creche parece assumir mais fortemente a característica de uma sala de aula e o sujeito-criança a condição de sujeito-aluno. É um dos momentos em que a professora e a auxiliar investem-se de autoridade formal para transmitir 'uma' idéia de dever cumprido: 'A gente tem coisa para fazer'.

Deste modo, o momento da roda e as tensões a ela inerentes não se tratam de questões inéditas no campo das pesquisas em Educação, sobretudo no que tange às organizações do trabalho pedagógico junto às crianças pequenas em instituições de Educação Infantil da Rede Municipal de Florianópolis, visto que, desde 1998, tais preocupações já estavam na pauta. Portanto, o momento da roda não se trata nem de "algo novo" enquanto proposta constitutiva da rotina de crianças na Educação Infantil do município, tampouco de uma organização destituída de problematizações, complexidades, análises e desafios.

\section{Últimas considerações}

Como últimas, mas não findadas considerações, indicamos que a escolha por uma instituição de Educação Infantil como lócus da pesquisa não se deu de forma arbitrária, mas na certeza de que este espaço se constitui como revelador das formas regulatórias que marcam uma das principais características da Modernidade. Portanto, todas as organizações sociais são compostas por regras que regulam a vida coletiva de seus participantes e, esse conjunto de formas regulatórias, também se faz presente nas instituições de Educação Infantil.

Sublinhamos que as regras são essenciais para a convivência em sociedade, no sentido de organizar os interesses e necessidades dos sujeitos que a compõem. Contudo, à luz de uma pesquisa etnográfica no contexto investigado foi possível evidenciar que, em certas circunstâncias e eventos, havia um excesso de regulação das ações e condutas das crianças, reprimindo suas manifestações, brincadeiras e interações e pouco, ou nada contribuindo para a vida comum em um contexto de educação coletiva.

Buscamos, com este texto, valorizar o momento da roda de conversa como potente para a garantia do direito à participação das crianças sobre as decisões que afetam seu cotidiano educativo, e que, a expressão das crianças possa compor a organização as práticas pedagógicas. A pesquisa empírica, realizada junto às crianças e professoras do Grupo 4/5 na instituição de Educação Infan- 
til, trouxe à tona algumas das complexidades e tensões envoltas ao momento da roda de conversa, especialmente quanto à garantia do direito à participação das crianças, sublinhando desafios enfrentados pelos adultos que compõem a relação educativa e pedagógica e que não se limitam à realidade observada, mas permeiam também outros coletivos.

Nesse meandro, reconhecemos a insuficiência de apenas ouvir as vozes das crianças no momento da roda de conversa e destacamos a urgência de que os sujeitos adultos, em suas práticas pedagógicas, pratiquem a ausculta como algo que ultrapassa as dimensões biológicas de escuta, envolvendo a compreensão da comunicação feita pelo outro. Ressaltamos, com isto, que compor o momento da roda de conversa de modo democrático e de garantia da participação das crianças é desafiador às professoras pela tradição adultocêntrica e moderna de incompletude da infância, que insiste em atravessar a docência na Educação Infantil, mas, possível, se articulado a uma reflexão permanente sobre as formas de organizar o cotidiano educativo, de modo a colocar-se criticamente diante de formas regulatórias autoritárias, buscando a garantia do direito a participação das crianças em momentos que não se limitam a roda de conversa, mas carecem nela estar.

A potência de trazer à tona o momento da roda em tensão ao direito à participação reside em demarcar o quanto ainda se faz preciso e necessário legitimarmos a competência das crianças como sujeitos que possuem direitos de exercício da cidadania, sendo a participação uma de suas frentes. Neste prisma, a participação enquanto direito transcende o momento da roda e vai ao encontro da construção de um outro modo de compreendermos as crianças e nos relacionarmos com elas. Modo este distinto ao que o paradigma Moderno nos ensina. Assim, o horizonte aqui almejado encontra morada em um paradigma de alteridade às crianças e à sua infância, mas também de respeito por suas potencialidades e garantia de seus direitos.

Imbuídas pelas palavras de Boaventura de Sousa Santos (2002), indicamos que, para que a luta por um novo paradigma se efetive, é necessário realizar outras propostas, conceber as crianças de maneira distinta da que comumente é aceita, contrariando a concepção de falta, ausência e incompletude. É preciso buscar outros caminhos que levem à emancipação, que superem a regulação pautada na racionalidade. Ou seja, faz-se urgente a busca pela superação de práticas nas quais os adultos são os únicos a deter o poder, pois como são vistos como sujeitos racionais, lhes é concedido o direito de regular a vida das crianças, lançando mão de instrumentos regulatórios como o momento da roda. 


\section{REFERÊNCIAS}

AGOSTINHO, Kátia Adair. O espaço da creche: que lugar é esse? 2003. Dissertação (Mestrado em Educação) - Centro de Ciências da Educação, Universidade Federal de Santa Catarina. Florianópolis, 2003.

BARBOSA, Maria Carmem Silveira. Por amor e por força: as rotinas na Educação Infantil. 2000. Tese (Doutorado em Educação) - Universidade Estadual de Campinas, Campinas, 2000.

BATISTA, Rosa. A rotina no dia-a-dia da creche: entre o proposto e o vivido. 1998. Dissertação (Mestrado em Educação) - Universidade Federal de Santa Catarina. Florianópolis, 1998.

BORGES, Luana Ferreira. Rotinas da educação infantil nas instituições municipais de Goiânia: um estudo a partir das atividades do sono e do banho na construção da identidade corporal das crianças. 2017. Dissertação (Mestrado em Educação) - Pontifícia Universidade Católica de Goiás. Goiânia, 2017.

BRASIL. Constituição da República Federativa do Brasil. Brasília, DF: Senado Federal, 1988.

CERVI, Gicele Maria. Política de gestão escolar na sociedade de controle. 2010. Tese (Doutorado em Educação) - Pontifícia Universidade Católica de São Paulo. São Paulo, 2010.

DE ÂNGELO, Adilson. O espaço-tempo da fala na Educação Infantil: a roda de conversa como dispositivo pedagógico. In: ROCHA, Eloisa Acires Candal; KRAMER, Sônia. (Orgs.). Educação Infantil: enfoques em diálogo. Campinas: Papirus, 2013. p. 53-66.

FERNANDES, Nathália. Infância e direitos: participação das crianças nos contextos de vida: representações, práticas e poderes. 2005. Tese (Doutorado em Sociologia da Infância) - Universidade do Minho. Braga, 2005.

GONÇALVES, Gisele. A criança como sujeito de direitos: um panorama da produção acadêmica brasileira (1987-2013). 2015. Dissertação (Mestrado em Educação) - Universidade Federal de Santa Catarina. Florianópolis, 2015.

JAMES, Allison; PROUT, Alan (Orgs.). Constructing and Reconstructing Childhood: Contemporany Issues in the Sociological Study of Childhood. London: The Falmer Press, 1990.

LOPES, Jader Janer Moreira. Geografia da Infância: contribuições aos estudos das crianças e suas infâncias. Educação Pública, v. 22, n. 49/1, p. 283-294, 2013.

MOTTA, Flávia. Salada de crianças: a roda de conversas com prática dialógica. In: ROCHA, Eloisa Acires Candal; KRAMER, Sônia (Orgs.). Educação Infantil: enfoques em diálogo. Campinas: Papirus, 2013. p. 67-84. 
MOURA, Marianne da Cruz. A rotina de crianças de zero a dois anos na educação infantil e as especificidades infantis. 2012. Dissertação (Mestrado em Educação) - Universidade Federal do Rio Grande do Norte. Natal, 2012.

NASCIMENTO, Edaniele Cristine Machado do. A rotina com bebês e crianças bem pequenas nos centros municipais de educação infantil de Guarapuava-PR: invisibilidades e silenciamentos. 2015. Dissertação (Mestrado em Educação) - Universidade Estadual do Centro-Oeste. Guarapuava, 2015.

ONU. Convenção sobre os Direitos da Criança. Adotada pela Assembleia Geral nas Nações Unidas em 20 de novembro de 1989. Disponível em: https://www.unicef.org/ brazil/convencao-sobre-os-direitos-da-crianca. Acesso em: jun.2019.

ROCHA, Eloisa Acires Candal. Por que ouvir as crianças? Algumas questões para um debate científico multidisciplinar. In: CRUZ, Silvia Helena Vieira (Org). A criança fala: a escuta de crianças em pesquisas. São Paulo: Cortez, 2008. p. 43-51.

ROCHA, Ruth. Os direitos das crianças segundo Ruth Rocha. São Paulo: Moderna, 2002.

RODRIGUES, Charlene de Oliveira. A construção das rotinas: caminhos para uma educação infantil de qualidade. 2009. Dissertação (Mestrado em Educação) - Universidade de Brasília. Distrito Federal, 2009.

ROSA, Glenda Matias de Oliveira. No descomeço era o verbo: Manoel de Barros e a roda de conversa na educação infantil. Curitiba: Appris, 2018.

SANTOS, Boaventura de Sousa. Para uma sociologia das ausências e uma sociologia das emergências. Revista Crítica de Ciências Sociais, n. 63, p. 237-280, 2002.

SOUZA, Natalya Camargo de. Rotinas e mediações na pré-escola. 2013. Dissertação (Mestrado em Educação) - Universidade Estadual Paulista Júlio de Mesquita. Presidente Prudente, 2013.

Texto recebido em 15/05/2019.

Texto aprovado em 09/07/2019. 